\section{Acute coronary spasm during posterior fossa surgery and its successful management: A variable presentation of trigemino cardiac reflex}

Sir,

Haemodynamic fluctuations and arrhythmias are common during posterior fossa surgeries due to brainstem handling. However, acute coronary spasm during the cerebellopontine angle tumour excision is a rare event. Only a few reports of coronary spasm have been reported in the literature. ${ }^{[1-4]}$ We report a case of acute intraoperative coronary spasm due to stimulation of trigeminal nerve and its successful management.

A37-year-old AmericanSociety of Anesthesiologists (ASA) Grade 1 woman (height $154 \mathrm{~cm}$, weight $64 \mathrm{~kg}$ ) underwent a right retromastoid suboccipital re-craniotomy and excision of a recurrent vestibular schwannoma [Figure 1] in left lateral position. Patient was anaesthetised using propofol $(3 \mathrm{mg} / \mathrm{kg})$, fentanyl $(3 \mu \mathrm{g} / \mathrm{kg})$ and vecuronium $(0.15 \mathrm{mg} / \mathrm{kg})$. Anaesthesia was maintained using air, oxygen and isoflurane (0.9-1 minimum alveolar concentration) and vecuronium infusion. She was haemodynamically stable until the dural opening.

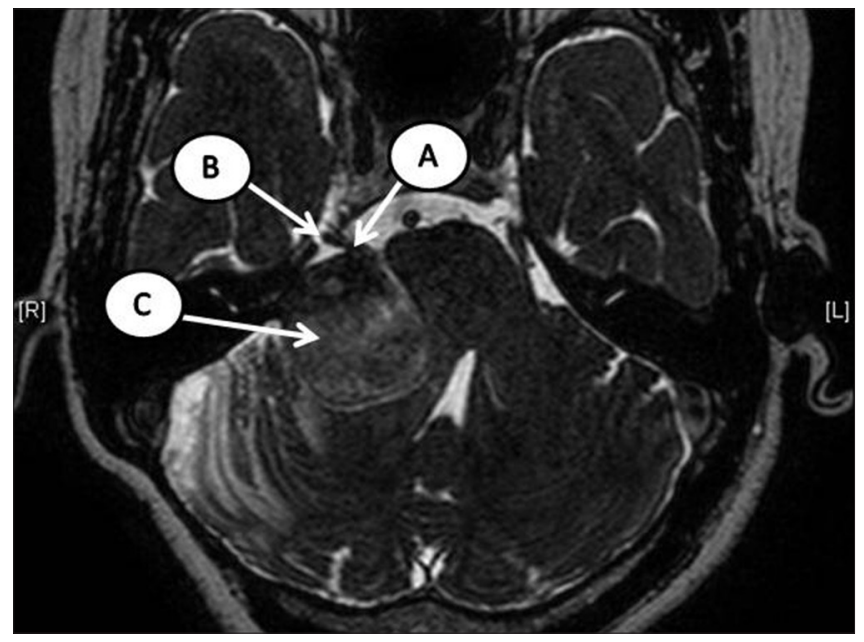

Figure 1: Magnetic resonance imaging brain (T2-weighted drive) shows the vestibular schwannoma with distorted trigeminal nerve. A: Trigeminal nerve, B: Meckel's cave, C: Vestibular schwannoma
During the internal decompression of the lesion, the pulse rate increased from 90 to 116 beats/min. Anaesthesia was further deepened with bolus doses of propofol and fentanyl. Despite adequate analgesics $(6 \mu \mathrm{g} / \mathrm{kg}$ fentanyl), anaesthetic depth and muscle relaxation, there was a persistent tachycardia, which was treated with $4 \mathrm{mg}$ of metaprolol ( $1 \mathrm{mg}$ bolus). However, there was no significant reduction in heart rate even after treating with metaprolol, and the blood pressure (BP) started to increase from 110 to $140 \mathrm{mmHg}$ and persisted at that value for more than $30 \mathrm{~min}$. We attempted to reduce the $\mathrm{BP}$ with labetalol boluses (5 mg each) up to $15 \mathrm{mg}$, so as to reduce the surgical bleeding due to high $\mathrm{BP}$, which failed to bring down the BP [Figure 2]. While the surgeon was resecting the superior pole of the lesion, there was a sudden sharp increase in systolic BP from 130 to $175 \mathrm{mmHg}$ with severe ST segment depression on electrocardiogram [Figure 2]. The ST segment went down from baseline of -0.3 to -2.4 over a period of 3-4 min [Figure 3]. A possibility of acute coronary spasm due to trigeminal nerve stimulation was suspected. This was notified to the surgeon, and the further dissection of the lesion was stopped. This acute rise in BP was treated with fentanyl $(50 \mu \mathrm{g})$, propofol $(50 \mathrm{mg})$, and esmolol ( $40 \mathrm{mg}$ ). A glycerol trinitrate (GTN) infusion was started at the rate of $0.5 \mu \mathrm{g} / \mathrm{kg} / \mathrm{min}$ to treat the coronary spasm and to control the BP. After starting the GTN, ST depression improved from -2.4 to -1.4 over a period of $30 \mathrm{~min}$. Hence, we had decided to proceed with the surgery. The dissection was continued, but, the BP started to rise again that was treated by increasing the dose of GTN $(1.5-2.0 \mu \mathrm{g} / \mathrm{kg} / \mathrm{min})$. Cardiac enzymes were sent, and a transthoracic echo was performed, which revealed no regional wall motion abnormality. The surgery was continued, and the lesion was excised completely.

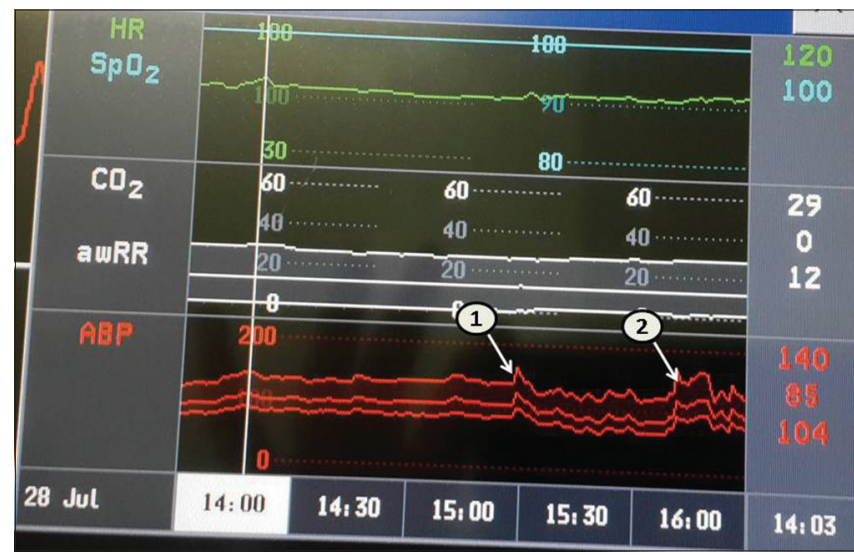

Figure 2: Haemodynamic changes from the time of dural opening to $30 \mathrm{~min}$ after the coronary spasm. (Arrow 1) the period at which hypertension and ST depression occurred. (Arrow 2) Episodes of hypertension following the restart of surgery 




Figure 3: The trends of ST segment changes during the episode of coronary spasm

A transdermal GTN patch (5 mg/24 h) was applied at the time of surgical closure, and the intravenous GTN was slowly tapered and stopped at the end of surgery. The patient was reversed and extubated smoothly. The ST segment was almost normalised $(-0.8)$ at the time of extubation. The initial cardiac enzymes and a repeat one done after $6 \mathrm{~h}$ were within normal limits. The GTN patch was continued for $24 \mathrm{~h}$ in the Neonatal Intensive Care Unit. Her post-operative period was uneventful and got discharged from hospital on the $5^{\text {th }}$ post-operative day.

The trigemino cardiac reflex (TCR) is a brain stem reflex with the trigeminal nerve being afferent and the vagus nerve being efferent. Its classical presentation is characterised by sudden hypotension, bradycardia, asystole, apnoea and hyper gastric motility. The classic presentation of TCR is seen only when there is central stimulation of the trigeminal nerve. ${ }^{[4]}$ Peripheral nerve stimulation or stimulation at Gasserian ganglion (located in Meckel's cave) usually presents with tachycardia and hypertension rather hypotension and bradycardia. This is because the sympathetic fibers from carotid plexus lie on the medial side of the Gasserian ganglion. ${ }^{[5]}$ In our case, the sudden hypertension was due to the sudden traction of the trigeminal nerve near the Meckel's cave. There was no further increase in heart rate noted during this event, possibly due to the administration of beta blockers before this event.

The sudden significant ST depression could be due to acute coronary spasm caused by the vagal stimulation. ${ }^{[4]}$ Beta-blocker administration for the treatment tachycardia could have worsened this spasm by causing unopposed alpha stimulation. ${ }^{[6]}$ A normal $\mathrm{PaCO}_{2}$ and electrolytes ruled out a possibility of hypocapnia or electrolyte imbalance induced ST depression.

Cardiac emergencies can happen even in ASA 1 patients who undergo non-cardiac surgery; the decision to proceed or stop the surgery depends on the individual case and their response to treatment. To reduce the heart rate and $\mathrm{BP}$, administration of labetalol (combined alpha and beta blocker) is a better choice, compared to administration of beta-blockers alone to avoid the unopposed alpha stimulating effect. Eternal vigilance, prompt diagnosis and its immediate treatment, better communication had prevented the cardiac morbidity in our case.

\section{Financial support and sponsorship Nil.}

\section{Conflicts of interest}

There are no conflicts of interest.

\section{Ramamani Mariappan, Krishna Prabhu ${ }^{1}$}

Departments of Anaesthesia and ${ }^{1}$ Neurological Sciences, Christian Medical College, Vellore, Tamil Nadu, India Address for correspondence: Dr. Ramamani Mariappan, Department of Anaesthesia, Christian Medical College, Vellore, Tamil Nadu, India. E-mail: ramamani@cmcvellore.ac.in

\section{REFERENCES}

1. Kotake Y, Matsumoto M, Yorozu T, Takeda J. Recurrent ST-segment elevation on ECG and ventricular tachycardia during neurosurgical anesthesia. J Anesth 2009;23:115-8.

2. Harada K, Nogami Y, Morimoto Y. Coronary artery spasm during neurosurgical anesthesia. Masui 2011;60:1169-72.

3. Kariya N, Toyoyama H, Furuichi K, Kubota H, Toyoda Y. Coronary artery spasm induced by trigeminal nerve stimulation and vagal reflex during intracranial operation. J Neurosurg Anesthesiol 1999;11:203-5.

4. Chowdhury T, Meuwly C, Sandu N, Cappellani RB, Schaller B. Coronary spasm in neurosurgical patients and role of trigeminocardiac reflex. Neurol Res Int 2014;2014:974930.

5. Chowdhury T, Petropolis A, Cappellani RB. Cardiac emergencies in neurosurgical patients. Biomed Res Int 2015;2015:751320.

6. Robertson RM, Wood AJ, Vaughn WK, Robertson D. Exacerbation of vasotonic angina pectoris by propranolol. Circulation 1982;65:281-5.

This is an open access article distributed under the terms of the Creative Commons Attribution-NonCommercial-ShareAlike 3.0 License, which allows others to remix, tweak, and build upon the work non-commercially, as long as the author is credited and the new creations are licensed under the identical terms.

\begin{tabular}{|l|l|}
\hline \multicolumn{2}{|c|}{ Access this article online } \\
\hline Quick Response Code: & Website: \\
\hline & www.jnaccjournal.org \\
\cline { 2 - 2 } & \\
\hline
\end{tabular}

How to cite this article: Mariappan R, Prabhu K. Acute coronary spasm during posterior fossa surgery and its successful management: A variable presentation of trigemino cardiac reflex. J Neuroanaesthesiol Crit Care 2016;3:157-8. 